Article

\title{
Optimization of Feedforward Neural Networks Using an Improved Flower Pollination Algorithm for Short-Term Wind Speed Prediction
}

\author{
Yidi Ren ${ }^{1,2}$, Hua Li ${ }^{1,2}$ and Hsiung-Cheng $\operatorname{Lin}^{3, *(D)}$ \\ 1 State Key Laboratory of Reliability and Intelligence of Electrical Equipment, School of Electrical Engineering, \\ Hebei University of Technology, Tianjin 300131, China; renyidi@yeah.net (Y.R.); lihua69@hebut.edu.cn (H.L.) \\ 2 Key Laboratory of Electromagnetic Field and Electrical Apparatus Reliability of Hebei Province, \\ School of Electrical Engineering, Hebei University of Technology, Tianjin 300131, China \\ 3 Department of Electronic Engineering, National Chin-Yi University of Technology, Taichung 41170, Taiwan \\ * Correspondence: hclin@ncut.edu.tw
}

Received: 4 September 2019; Accepted: 25 October 2019; Published: 29 October 2019

check for updates

\begin{abstract}
It is well known that the inherent instability of wind speed may jeopardize the safety and operation of wind power generation, consequently affecting the power dispatch efficiency in power systems. Therefore, accurate short-term wind speed prediction can provide valuable information to solve the wind power grid connection problem. For this reason, the optimization of feedforward (FF) neural networks using an improved flower pollination algorithm is proposed. First of all, the empirical mode decomposition method is devoted to decompose the wind speed sequence into components of different frequencies for decreasing the volatility of the wind speed sequence. Secondly, a back propagation neural network is integrated with the improved flower pollination algorithm to predict the changing trend of each decomposed component. Finally, the predicted values of each component can get into an overlay combination process and achieve the purpose of accurate prediction of wind speed. Compared with major existing neural network models, the performance tests confirm that the average absolute error using the proposed algorithm can be reduced up to $3.67 \%$.
\end{abstract}

Keywords: wind speed forecasting; flower pollination algorithms; feedforward neural network; ensemble empirical mode decomposition

\section{Introduction}

Natural energy sources like oil, coal and gas used for power generation are usually environmentally destructive in their harvesting to produce usable energy. They are gone forever when they are used up. Therefore, natural and renewable energy resources from the earth are highly desired. In recent years, wind power has become a new sustainable and renewable alternative to burning fossil fuels, which has a much smaller impact on the environment. With the rapid increase in large-scale wind farms, wind power generation continues to rise in the power industry [1]. For example, renewable energy has generated 72,896 kW power during 2018 in China, with wind power accounting for $25.3 \%$ of all this renewable energy capacity [2]. However, the stochasticity and intermittent nature of wind speed may result in an obvious disturbance to the power system and thus affect the power quality. Accordingly, the security and stability of power systems are facing more challenges than before [3]. If the prediction of wind speed can be more accurate, distribution and reserve capacity can be more effectively rationalized through wind turbines. Accordingly, the electricity power spare capacity can be reduced considerably so that smart grids can be achieved [4-7].

Physical or statistical methods were usually used for wind speed prediction [8-10]. In the physical method, for instance, based on the numerical weather prediction model (NWP), a Kalman filter is 
added for wind speed prediction [11]. However, it requires a large amount of calculations and has a low precision. In [12], the combining of a fuzzy system with a cuckoo search (CS) algorithm was proposed. Compared with the NWP model, this kind of model requires less computation, is faster and more convenient to use. Alternatively, statistical methods, such as time series, support vector machine (SVM) and artificial neural network (ANN), can present a simpler way than the physical methods, but the complexity process of wind speed generation was not fully considered [13]. ANN may suffer from a trapped local optimum and slow convergence speed. Its convergence efficiency may also affect the accuracy of wind speed forecast. On the other hand, a SVM model was reported to improve the function of fluctuating wind speed forecast [14]. Its generalization ability, however, was not enough for the wind speed prediction performance. In [15], the SVM was modified by a new algorithm to reduce the limitations of the model. However, the wavelet basis still has difficulty to achieve an ideal decomposition in the wind speed sequence [16]. In [17], the gray correlation analysis method connected with V-Support Vector Machine (V-SVM) was applied for wind speed prediction. This method has a strong ability for nonlinear fitting, which can realize the wind speed prediction. However, the accuracy is sensitive to the selection of useful fluctuation information from the wind turbine generators. In [18], the LSSVM model predicted the wind speed by integrating the particle swarm optimization (PSO) and gravity search algorithms. A great number of data was demanded to implement the proposed model. In [19], the output and actual situation for wind speed forecast in view of different neural networks were studied and compared. Although the generalization abilities of various models were analyzed, the suitability for different wind farms was not sufficiently unveiled. In [20], the instability of wind speed forecast brought very great difficulty. In this model, a regression model is devoted to predict wind speed, but its forecasting accuracy is still insufficient. In [21], the wind speed sequence is decomposed by the empirical mode decomposition method before prediction. However, the mode aliasing phenomenon may occur and result in an incomplete decomposition.

In the second section of this paper, the principles of feedforward (FF) neural networks and the flower pollination algorithm are introduced. Further, the improved flower pollination algorithm (IFPA) is proposed by adding dynamic inertia weight. Based on IFPA, FF is optimized, and its convergence performance is improved. In Section 3, the ensemble empirical mode decomposition (EEMD) algorithm is presented to deal with the wind speed data. Consequently, the EEMD-IFPA-FF prediction model is established. The forecasting results from EEMD-IFPA-FF, EEMD-FPA-FF and IFPA-FF models are also discussed and compared for details. The conclusions are given in Section 4.

\section{Establishment of Forecasting Model}

\subsection{The Fundamentals of the FF Model}

The feedforward (FF) neural network used in this paper is based on a multi-layer feedforward network, which is composed of three layers [22,23]. It can efficiently train the network using a gradient-based optimization algorithm. The network weights and thresholds that connect the input layer and output layer keep updatingiteratively to reduce the error until it reaches the desired task for which it is being trained. The procedures to implement the FF model are shown as follows:

(1) Initialize all connection weight $v$ and threshold $b$ using small random numbers.

(2) Determine the structure of the FF model, input training samples and predictive output samples.

(3) Calculate the outputs of the hidden layer under Equation (1) and the output layer under Equation (2) based on the forward propagation process.

$$
\theta_{j}^{1}=f\left(\sum_{j}^{S_{1}} v_{j i}^{1} x_{i}+b_{j}^{1}\right), j=1,2, \ldots S_{1}
$$




$$
\theta_{k}^{2}=g\left(\sum_{j}^{S_{2}} v_{k j}^{2} x_{j}+b_{k}^{2}\right), k=1,2, \ldots S_{2}
$$

where $\theta_{j}^{1}$ is the output of the hidden layer; $f$ is the transfer function of the hidden layer; $v_{j i}^{1}$ is the connection weight; $x_{i}$ is the node of the input layer; $b_{j}^{1}$ is the threshold of the hidden layer; $S_{1}$ is the number of hidden layers; $\theta_{k}^{2}$ is the output layer; $g$ is the transfer function of the output layer; $v_{k j}^{2}$ is the connection weight; $x_{j}$ is the node of the hidden layer; $b_{k}^{2}$ is the threshold of the output layer; and $S_{2}$ is the number of output layers.

(4) Update weights and thresholds using the back-propagation process, as shown in Equation (3):

$$
n(i+1)=n(i)+\beta P(i)
$$

where $n(i+1)$ and $n(i)$ are the weights and thresholds at the $i+1$ and $i$ iteration, respectively; $\beta$ is a learning rate, and $P(i)$ is the negative gradient of the output error at the $i$ iteration, that is, the fastest direction in gradient.

(5) Repeat Steps (3) and (4) until the mean square error (E) reaches the predefined value:

$$
E=\frac{1}{2} \sum_{k}^{S_{2}}\left(t_{k}-\theta_{k}^{2}\right)^{2}
$$

where $S_{2}$ is the number of output layers; $t_{k}$ is the target value; and $\theta_{k}^{2}$ is the output value.

As above, FF may suffer from a weak global search ability, i.e., liable to be trapped into a local minimum. To solve this problem, some algorithms such as extreme learning machines, support vector machines, particle swarms and genetic algorithms are usually used to improve FF [24,25]. In this study, the improved flower pollination algorithm (IFPA) is developed to optimize the FF neural network.

\subsection{The Principle of IFPA}

The IFPA is developed from the base of the flower pollination algorithm (FPA). Usually, the FPA is performed under the following assumptions: (1) Biological allogamy is a pollinator flying through Levy to achieve a global pollination effect; (2) Self-pollination hypothesis is a local pollination procedure; (3) The reproduction rate of flowers is proportional to the rate of pollination; and (4) The transition between global pollination and local pollination is determined by physical factors, such as distance between flowers or wind speed. This conversion is represented in the algorithm by the conversion probability [26]. The FPA main steps are described below:

(1) Initializing the parameters, such as the number of flower population $\mathrm{N}$, the transformation probability parameters $P$ and a random number rand $\in(0,1)$ in FPA.

(2) Finding the global optimal solution by comparing the values of the fitness of each solution.

(3) If the conversion rate is $p>$ rand (a predefined value), the solution is updated, and the transboundary process is implemented in the light of Equation (5):

$$
u_{i}^{t+1}=u_{i}^{t}+L\left(g^{*}+u_{i}^{t}\right)
$$

where $u_{i}^{t+1}$ and $u_{i}^{t}$ represent the solutions of the $(t+1)^{t h}$ and $(t)^{t h}$ generation, separately; $g^{*}$ is the global optimum solution; $L$ is the step length produced by pollen propagator Levyflying; and $L$ obeys the Levy distribution, and its value is substituted into Equation (6):

$$
L \sim \frac{\lambda \Gamma(\lambda) \sin (\pi \lambda / 2)}{\pi s^{1+\lambda}}
$$


where $s>>s_{0}>0$, $s$ is the step dimension, and $s_{0}$ is the minimum step dimension; $\Gamma(\lambda)$ is the standard Gamma function, and select $\lambda=1.5$; and the Leavy flight step $L$ is generated under Mantegna's algorithm [26].

(4) If the conversion rate is $p \leq r a n d$, the solution is updated, and the transboundary process is implemented according to Equation (7):

$$
u_{i}^{t+1}=u_{i}^{t}+\gamma\left(u_{j}^{t}+u_{q}^{t}\right)
$$

where $\gamma$ is a random number on [0,1]; and $u_{j}^{t}$ and $u_{q}^{t}$ are pollen of flowers of the same plant species.

(5) Compute Steps (3) and (4) to get the fitness of the data processing. Judge whether the fitness of the new solution reaches the optimal position. If yes, the fitness and solution is updated. Otherwise, the current fitness and solution remains unchanged.

(6) If the fitness value of the global optimal is larger than the fitness value of the new solution value, then set a new solution as the global optimal solution.

(7) Judge whether the end qualification is satisfied. If the conditions are met, the output is certified as the optimal value. Otherwise, return to Step (3).

The principle of FPA indicates that the optimization solution mainly depends on the interaction between pollen individuals, which can be easily trapped into a local minimum. To resolve this problem, the inertia weight $\omega$ is introduced into the pollen position. The new position is updated using Equation (8):

$$
u_{i}^{t+1}=\omega \cdot u_{i}^{t}+L\left(g^{*}+u_{i}^{t}\right)
$$

At the beginning of the iteration, the larger weight of the previous generation pollen in FPA has a greater impact on the current pollen movement. The attraction between pollen is also smaller. Contrastively, the smaller inertia weight in the later iteration can make the attraction between pollen larger. In this situation, the local search power becomes stronger, while the global search power weakens. To avoid a repeated oscillation near the extreme point from a larger moving step size [26-29], four inertia weights, i.e., $\omega_{1}, \omega_{2}, \omega_{3}$ and $\omega_{4}$, are selected to improve FPA, where $\omega_{1}$ is a fixed inertia weight, $\omega_{2}$ is a linear inertia weight, $\omega_{3}$ is an exponential decreasing inertia weight and $\omega_{4}$ is a dynamic inertia weight. Each inertia weight is shown as follows:

$$
\begin{gathered}
\omega_{1}=0.6 \\
\omega_{2}=\omega_{\max }-\frac{\omega_{\max }-\omega_{\min }}{i_{\max }} \times i \\
\omega_{3}=\omega_{\min }+\left(\omega_{\max }-\omega_{\min }\right) e^{-\left(4 i / i_{\max }\right)^{2}} \\
\omega_{4}=\omega_{\max }-\left(\frac{i}{i_{\max }}\right)^{3} \times\left(\omega_{\max }-\omega_{\min }\right)
\end{gathered}
$$

where $\omega_{\max }$ is the biggest inertia weight; $\omega_{\min }$ is the minimum inertia weight; $i$ is the current value of iterations; and $i_{\max }$ is the maximum value of iterations. When the inertial weight varies from 0.9 to 0.4, the optimal searching effect can achieve the best solution [30]. For this reason, select $\omega_{\max }=0.9$, $\omega_{\min }=0.4$ and $i_{\max }=200$. The variation of four inertial weights vs. iteration number is shown in Figure 1.

\subsection{Convergence of IFPA}

In the study, there are four inertia weights, i.e., $\omega_{1}, \omega_{2}, \omega_{3}$ and $\omega_{4}$, added to IFPA. Rastrigin and Griewank functions are chosen for testing the global optimization performance. The population number, iteration number and conversion probability were set as 20, 200 and 0.8 , respectively [31,32]. The parameter settings environment is shown in Table 1. As shown in Table 2, the performance results 
are based on the average of 20 independent tests. It indicates that the optimal solution can be achieved by choosing $\omega_{4}$ in either a Rastrigin or Griewank function.

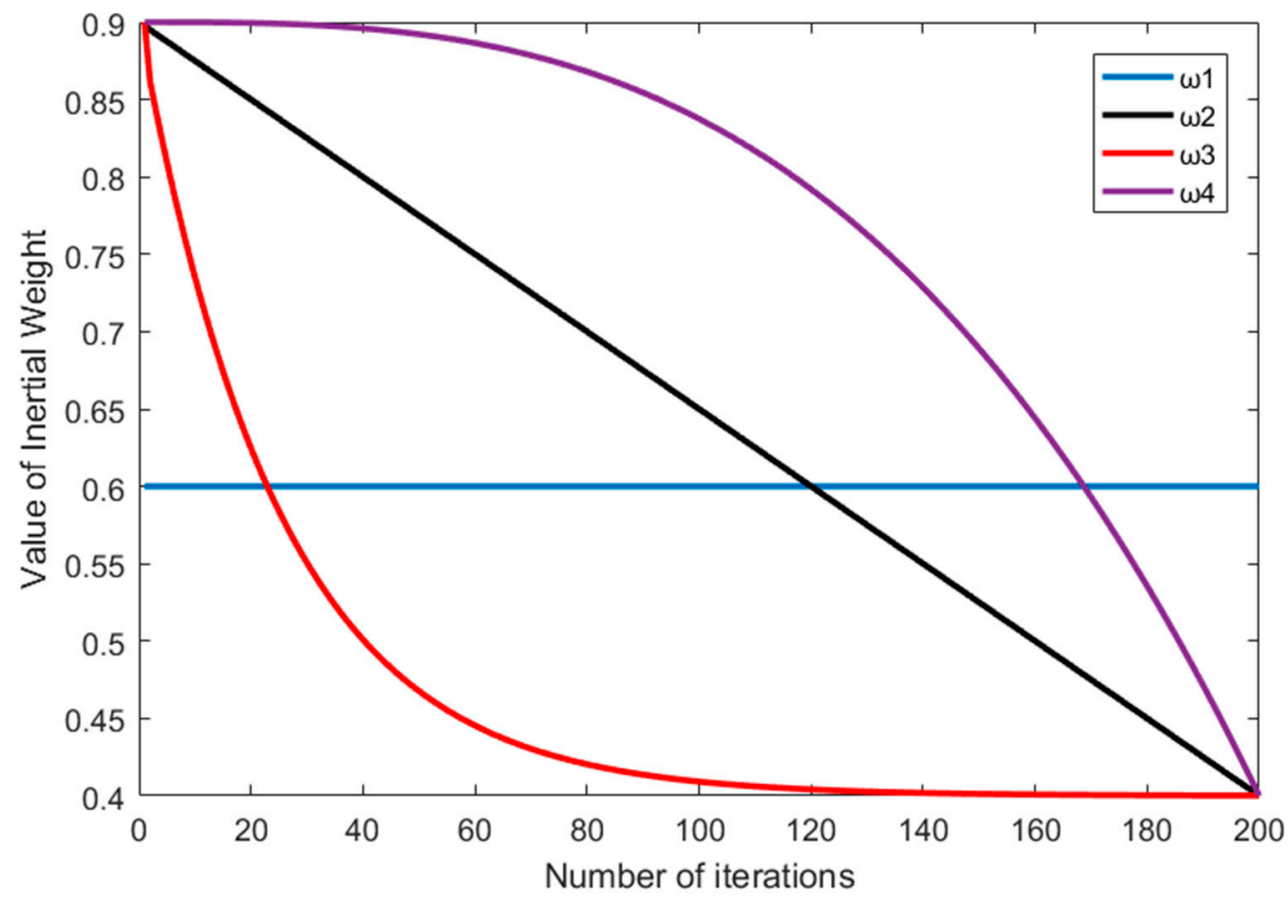

Figure 1. Variation of four inertial weights vs. iteration number.

Table 1. Parameter settings.

\begin{tabular}{ccc}
\hline Objective Function & Range & Optimal Value \\
\hline Rastrigin & $x \in[-5,5]$ & 0 \\
Griewank & $x \in[-8,8]$ & 0 \\
\hline
\end{tabular}

Table 2. Test results.

\begin{tabular}{ccccc}
\hline $\begin{array}{c}\text { Objective } \\
\text { Function }\end{array}$ & $\begin{array}{c}\text { Inertial } \\
\text { Weight }\end{array}$ & $\begin{array}{c}\text { Optimal } \\
\text { Convergence } \\
\text { Value }\end{array}$ & $\begin{array}{c}\text { Worst } \\
\text { Convergence } \\
\text { Value }\end{array}$ & $\begin{array}{c}\text { Average } \\
\text { Convergence } \\
\text { Value }\end{array}$ \\
\hline \multirow{3}{*}{ Rastrigin } & $\omega_{1}$ & 0.0001 & 0.0265 & 0.0265 \\
& $\omega_{2}$ & 0.0219 & 0.0313 & 0.0271 \\
& $\omega_{3}$ & $2.6130 \times 10^{-10}$ & 0.0003 & $2.6236 \times 10^{-08}$ \\
& $\omega_{4}$ & 0 & 0 & 0 \\
\hline \multirow{3}{*}{ Griewank } & $\omega_{1}$ & 0.0742 & 0.7001 & 0.0826 \\
& $\omega_{2}$ & 0.0213 & 0.1301 & 0.0213 \\
& $\omega_{3}$ & $3.6665 \times 10^{-10}$ & 0.2881 & $2.42 \times 10^{-10}$ \\
& $\omega_{4}$ & 0 & 0 & 0 \\
\hline
\end{tabular}

In Figure 2, the Rastrigin function is taken as the objective function. When the inertia weight is $\omega_{4}$, the optimal value is obtained in the $162^{\text {th }}$ generation. In Figure 3, the Griewank function is taken as the objective function. When the inertia weight is $\omega_{4}$, the optimal value is obtained in the $101^{\text {th }}$ generation. Moreover, it proves that $\omega_{4}$ can reach the fastest convergence speed among all parameters. 


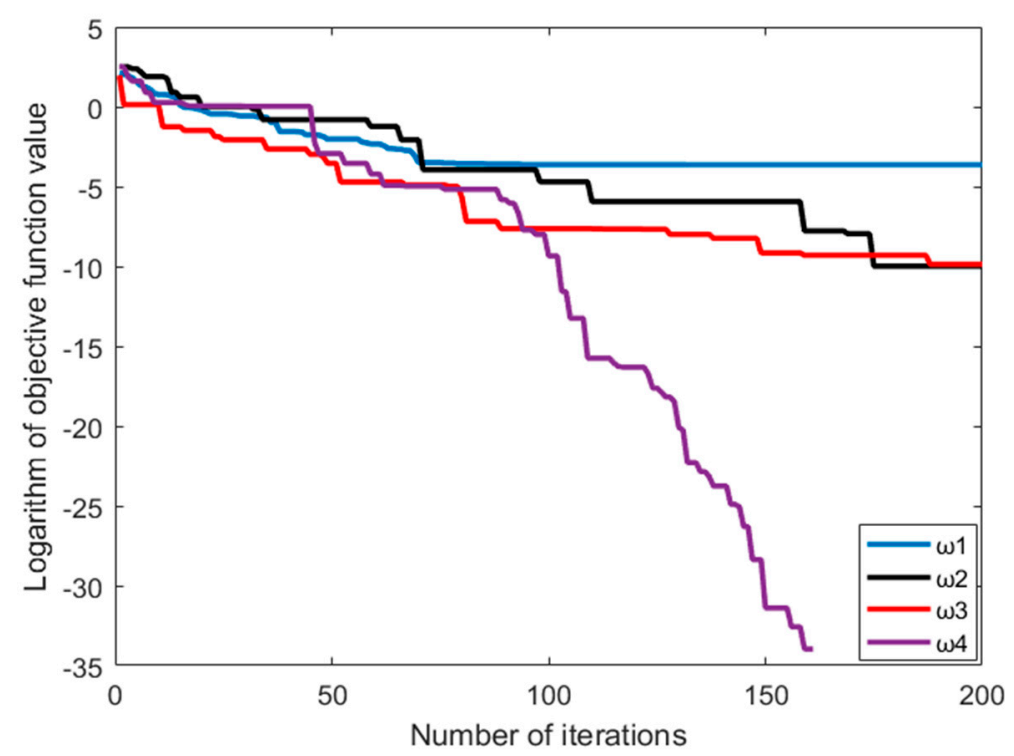

Figure 2. Iterative convergence curve from the Rastrigin function.

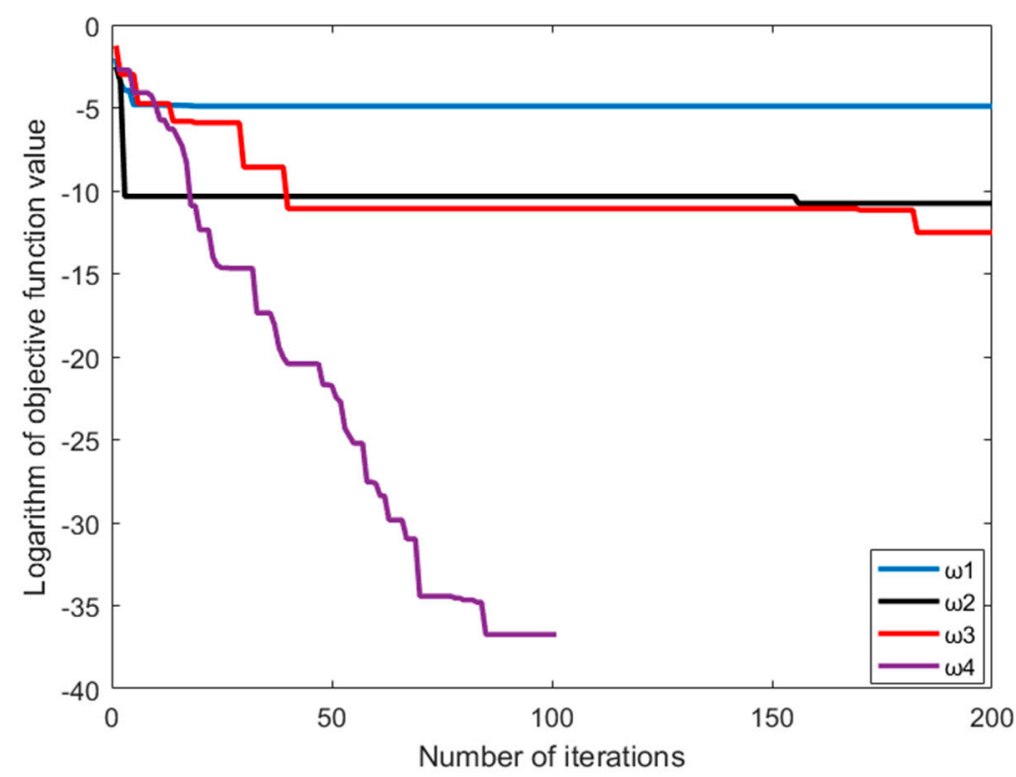

Figure 3. Iterative convergence curve from the Griewank function.

\subsection{Optimization of the FF Model Based on IFPA}

In this study, the IFPA is integrated with FF neural network to improve the optimization of FF weights and thresholds in the network. The Levy flight characteristics in IFPA are fully utilized for the global searching. Accordingly, the initial weight matrix and bias vector can be found and then given to FF neural network for the training procedure. Figure 4 shows the flow of IFPA-FF, and it is illustrated as follows:

(1) Initialize FF. Set input layer, hidden layer and output layer, initial network weight $v$ and initial thresholds $b$.

(2) Set the population number, the initial value of variation factor and network learning parameters, the maximum number of iterations and training end condition in IFPA algorithm.

(3) The initial weight $v$ and initial threshold $b$ in FF neural network are encoded into individual pollens $u$, where each pollen represents the FF neural network structure. 
(4) The speed and position of all pollens are initialized, and the objective function of each pollen is kept computing until the minimum fitness value is reached.

(5) A random value of rand is generated and compared with the conversion probability $p$. According to Equations (5) and (7) in FPA, the solution is kept being updated until the global optimal solution is reached.

(6) If the termination condition of IFPA is met, proceed to the next step. Otherwise, return to Step (5).

(7) The optimal pollen individual $u i$ is decoded, and the decoded weights $v i$ and $b i$ are used as connection weight $v$ and threshold $b$ for FF.

(8) If the ending condition of FF training is satisfied, the optimal network structure is thus obtained for further prediction. Otherwise, go back to Step (7).

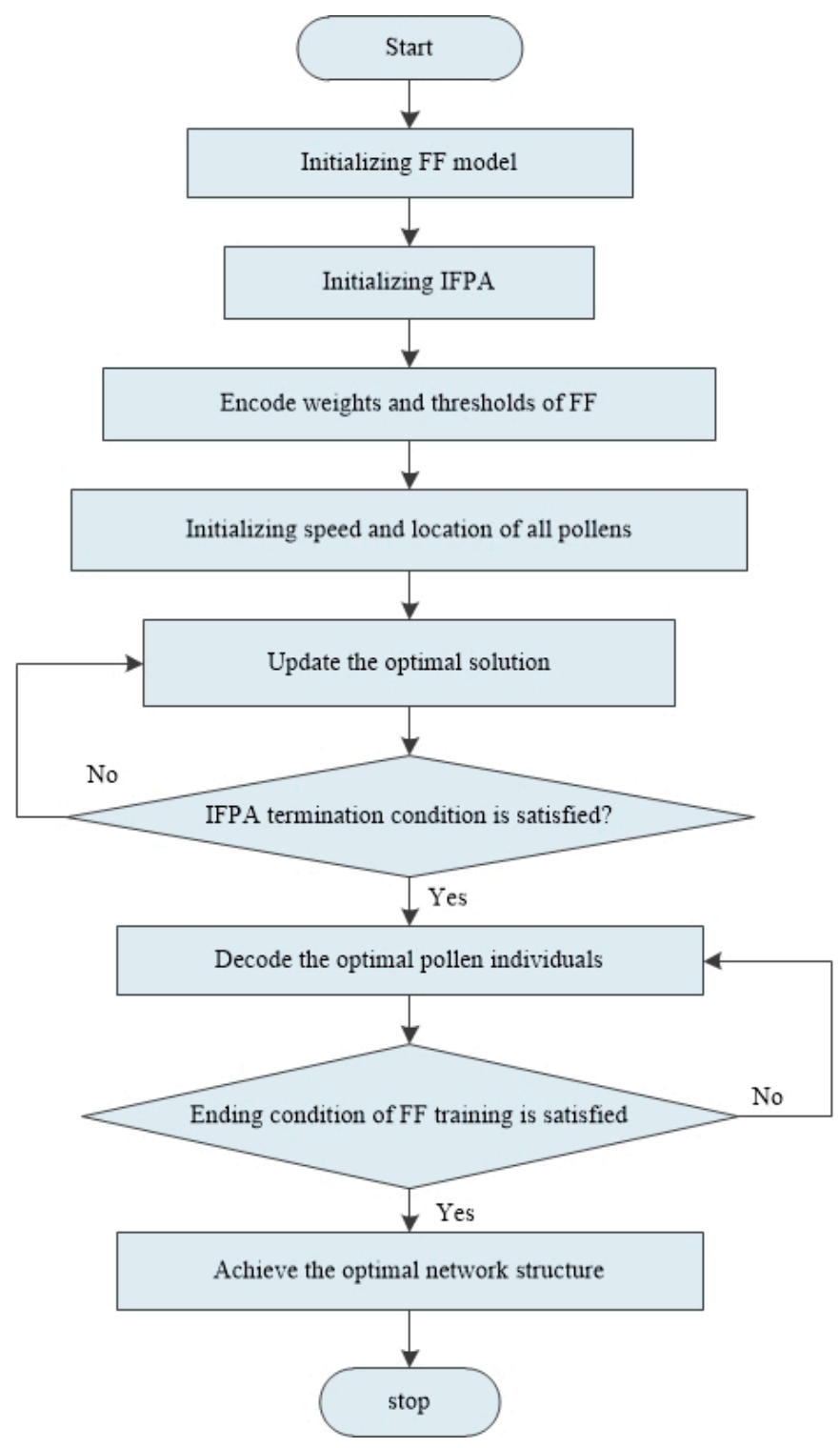

Figure 4. Flowchart of the improved flower pollination algorithm-feedforward (IFPA-FF) prediction model.

Schaffer and Ackley are used as objective functions to test the convergence performance in the IFPA and the FPA. The parameter settings environment is shown in Table 3. The population number, iteration number and conversion probability were set as 20,200 and 0.8, which are the same as the 
parameter settings in the above IFPA. The performance results shown in Table 4 are based on the average value from 20 independent tests.

Table 3. Parameter settings.

\begin{tabular}{ccc}
\hline Objective Function & Range & Optimal Value \\
\hline Schaffer & $x \in[-5,5]$ & 0 \\
Ackley & $x \in[-8,8]$ & 0 \\
\hline
\end{tabular}

Table 4. Test results.

\begin{tabular}{ccccc}
\hline $\begin{array}{c}\text { Objective } \\
\text { Function }\end{array}$ & Model & $\begin{array}{c}\text { Optimal } \\
\text { Convergence } \\
\text { Value }\end{array}$ & $\begin{array}{c}\text { Worst } \\
\text { Convergence } \\
\text { Value }\end{array}$ & $\begin{array}{c}\text { Average } \\
\text { Convergence } \\
\text { Value }\end{array}$ \\
\hline \multirow{2}{*}{ Schaffer } & IFPA & $3.3621 \times 10^{-79}$ & 0.0119 & $1.0221 \times 10^{-65}$ \\
& FPA & $1.1867 \times 10^{-15}$ & 0.0661 & 0.0001 \\
\hline \multirow{2}{*}{ Ackley } & IFPA & $2.5426 \times 10^{-74}$ & 0.0379 & $3.7926 \times 10^{-59}$ \\
& FPA & $2.1884 \times 10^{-05}$ & 0.0661 & 0.0661 \\
\hline
\end{tabular}

The iterative convergence curves using Schaffer and Ackley functions are shown in Figures 5 and 6, respectively. It can be seen that the IFPA model presents the best convergence performance in both of functions.

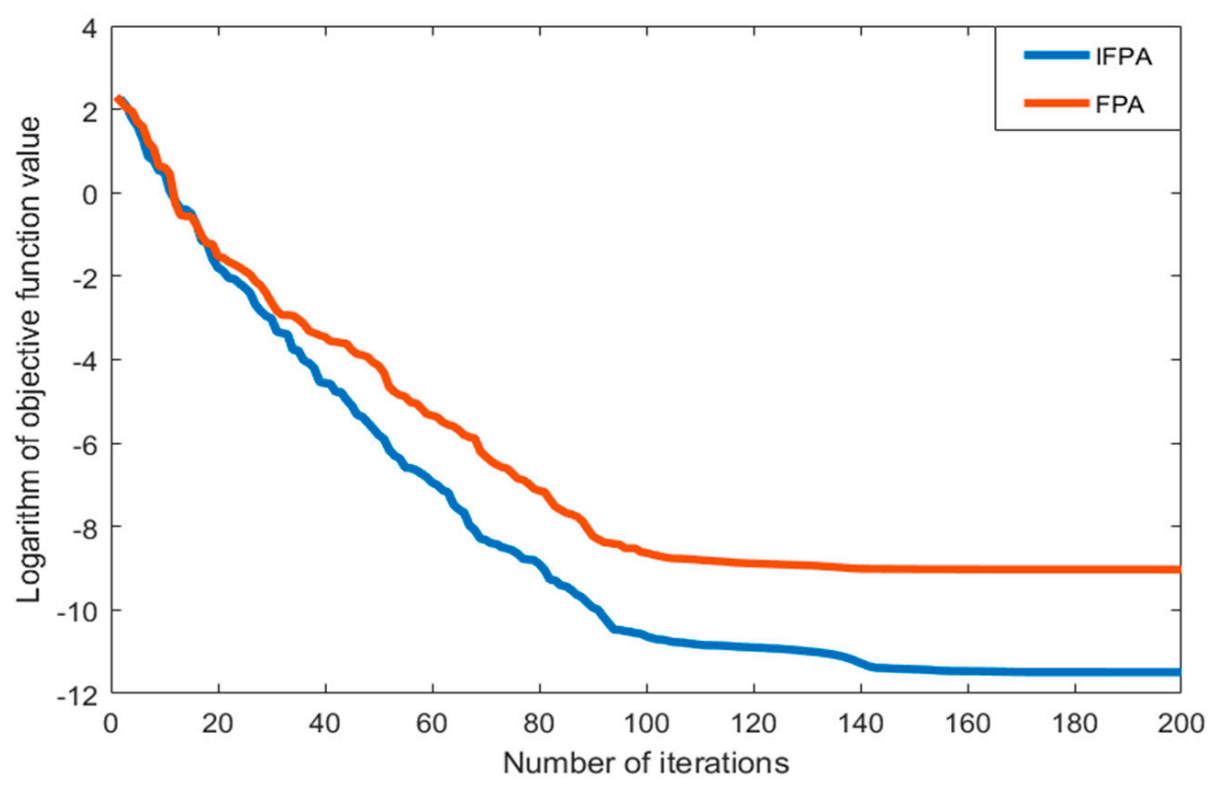

Figure 5. Iterative convergence curve from the Schaffer function. 


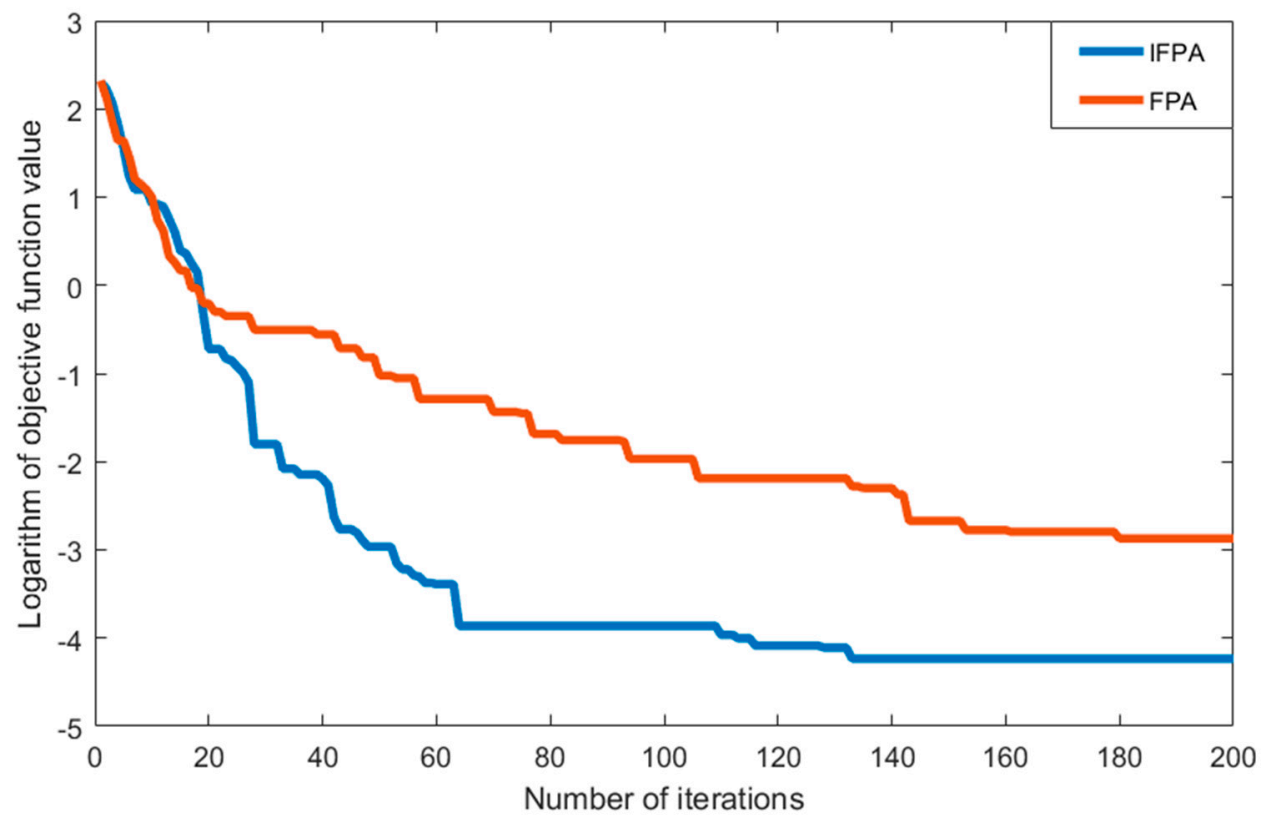

Figure 6. Iterative convergence curve from the Ackley function.

\section{Analysis of Wind Speed Forecasting}

\subsection{Preprocessing of Wind Speed Data}

The EEMD is an improved EMD model [33]. Based on EMD, a set of Gaussian white noise with normal distribution is added, which effectively improves the aliasing and discontinuity of signals at different scales and avoids the mode aliasing caused by EMD decomposition process [34-36]. The flowchart of EEMD is shown in Figure 7, illustrated as follows:

(1) A normal white Gaussian noise sequence $v(t)$ was added to the original sequence $g(t)$ to generate a new sequence $(u(t)=v(t)+g(t))$.

(2) Find the maximum and minimum values in $x(t)$ and fit the upper envelope $I_{\max }(t)$ and the lower envelope $I_{\min }(t)$ of $u(t)$.

(3) Calculate the average envelope $m(t)\left(=\frac{I_{\min }(t)+I_{\max }(t)}{2}\right)$, and subtract it from the noise sequence $u(t)$ to form a new sequence $p(t)(=u(t)-m(t))$.

(4) Justify if $p(t)$ satisfies the IMF. If yes, the IMF, denoted as $h_{1}(t)$, is confirmed. Otherwise, repeat Steps (1) and (2) until it is satisfied.

(5) The $h_{1}(t)$ is subtracted from the original sequence $u(t)$, and the residual component $r_{1}(t)\left(=u(t)-h_{1}(t)\right)$ is obtained.

(6) Repeat the same process from the first step until $r_{k}(t)$, as shown in Equation (13), becomes a monotone function.

(7) Finally, $u(t)$ is decomposed into $\mathrm{k}$ IMFs with different oscillation modes, as shown in Equation (14).

$$
\begin{gathered}
r_{2}(t)=r_{1}(t)-h_{2}(t) \\
r_{3}(t)=r_{2}(t)-h_{3}(t) \\
r_{4}(t)=r_{3}(t)-h_{4}(t) \\
\vdots \\
r_{k}(t)=r_{k-1}(t)-h_{k}(t) \\
u(t)=\sum_{i=1}^{k} h_{i}(t)+r_{k}(t)
\end{gathered}
$$




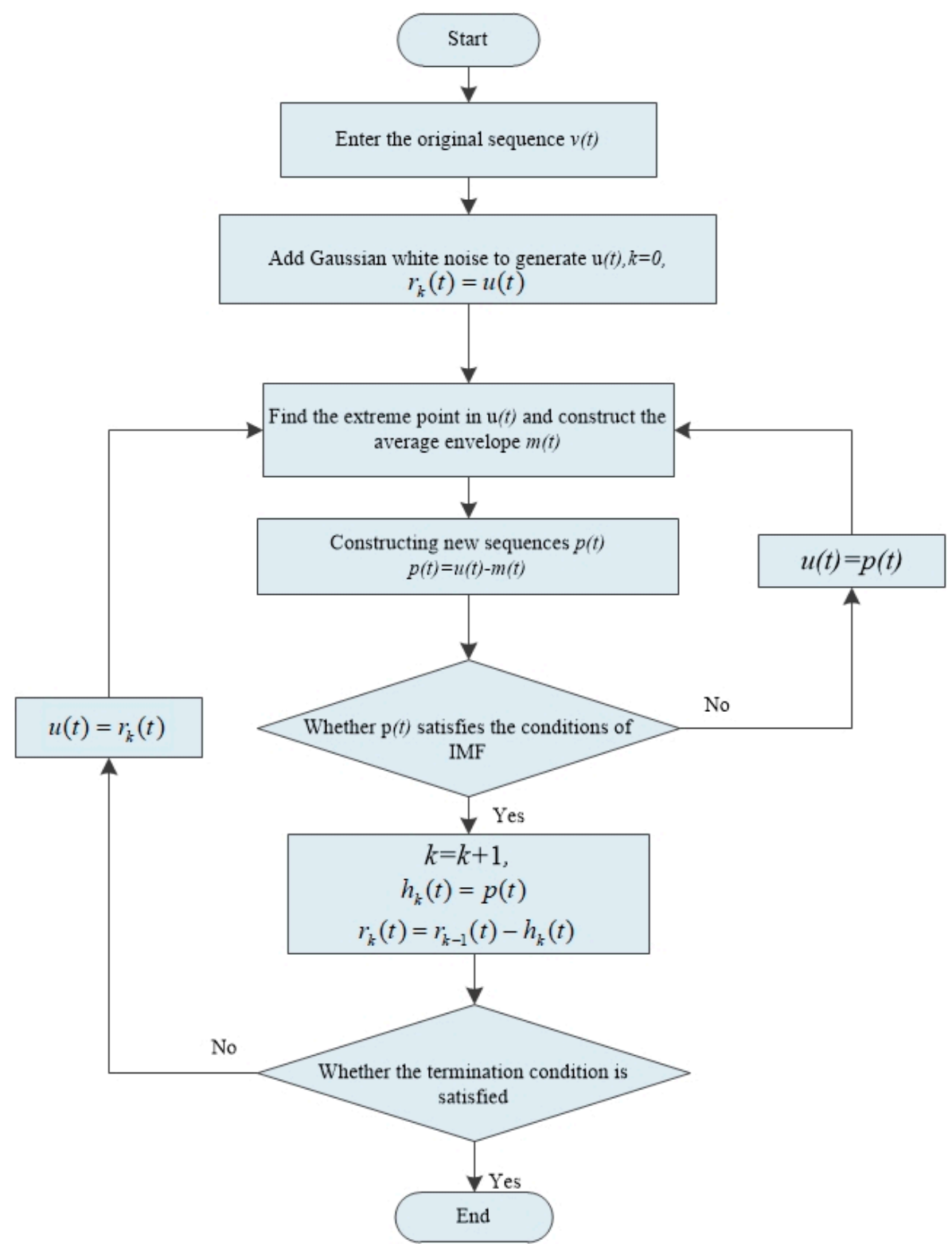

Figure 7. Flowchart of ensemble empirical mode decomposition (EEMD) implementation.

The data used in this study comes from the Sotavento wind farm in Galicia, Spain, and it is taken from 1 March to 13 March 2018. The wind speed statistics data is shown in Table 5. Sampling interval of wind speed data was $10 \mathrm{~min}$, as shown in Figure 8.

Table 5. Wind speed statistics data.

\begin{tabular}{cccccc}
\hline $\begin{array}{c}\text { Maximum } \\
(\mathbf{m} / \mathbf{s})\end{array}$ & $\begin{array}{c}\text { Minimum } \\
(\mathbf{m} / \mathbf{s})\end{array}$ & $\begin{array}{c}\text { Mean } \\
(\mathbf{m} / \mathbf{s})\end{array}$ & $\begin{array}{c}\text { Mode } \\
(\mathrm{m} / \mathbf{s})\end{array}$ & $\begin{array}{c}\text { Mid-Value } \\
(\mathrm{m} / \mathbf{s})\end{array}$ & $\begin{array}{c}\text { Standard Deviation } \\
(\mathbf{m} / \mathbf{s})\end{array}$ \\
\hline 15.18 & 2.28 & 7.47 & 8.82 & 7.51 & 2.59 \\
\hline
\end{tabular}




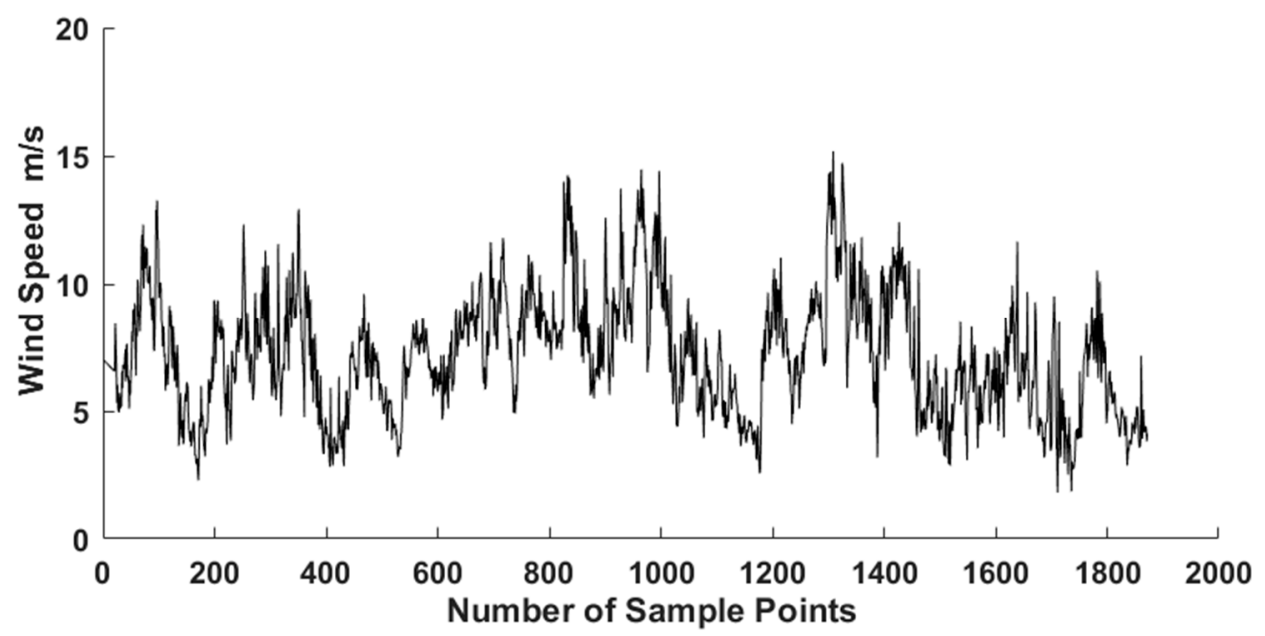

Figure 8. Raw data of wind speed.

From Table 5, it is seen that the real wind speed data is highly volatile and unpredictable. Based on the EEMD, it can be decomposed into several relatively stable series under different characteristic scales. The decomposition results are shown in Figure 9.

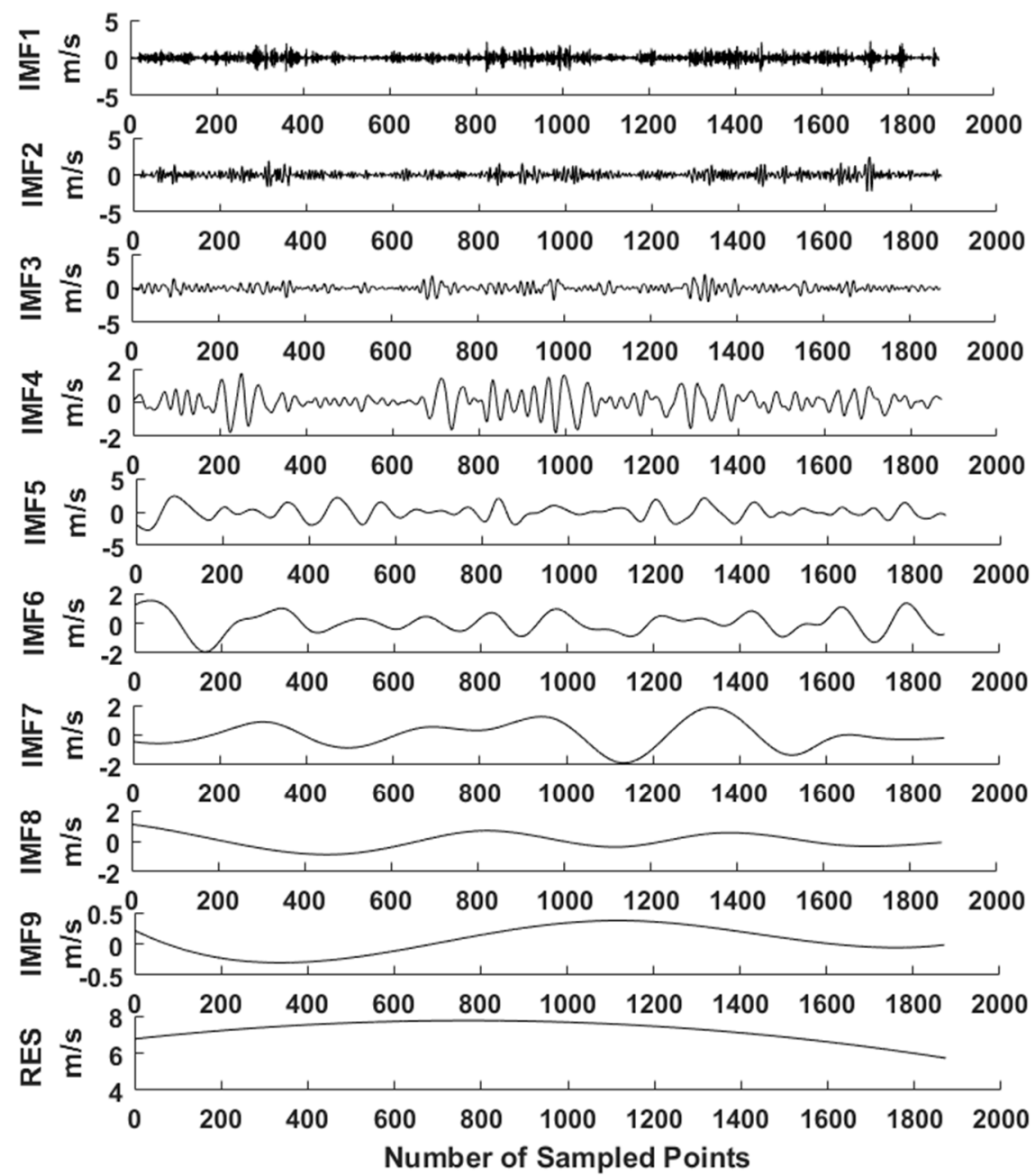

Figure 9. Data from EEMD decomposition. 
As shown in Figure 9, the frequency of each component is, in turn, from high to low, and the large fluctuation of high frequency component is the random influence part of wind speed. The low frequency component has the characteristics of a sinusoidal wave and is generally considered as the periodic component of wind speed. The symbol "RES" represents the trend component, indicating the long-term trend of wind speed. There are 10 decomposed sequences (IMF1, IMF2, . . , IMF9, RES) input into the IFPA-FF model for training. After the training process is completed, these 10 predicted components are superimposed to obtain the final prediction value for comparison with the real value. The flowchart of the prediction model is shown in Figure 10.

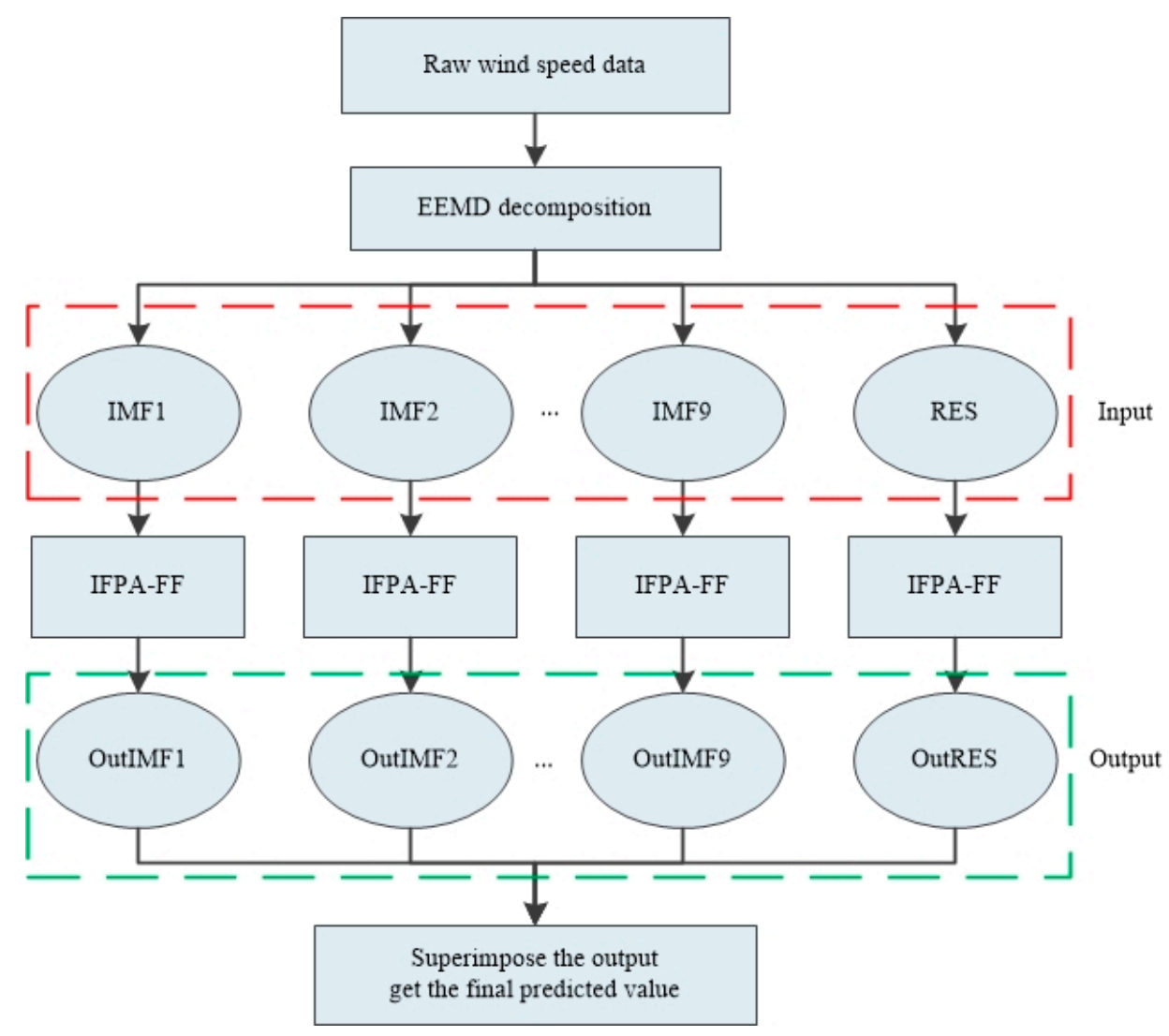

Figure 10. Flowchart of the prediction model.

\subsection{Wind Speed Forecasting Employed EEMD-IFPA-FF Model}

There are three error functions, i.e., MAE, RMSE and MAPE applied to evaluate the effectiveness of the proposed model. Besides, an indicator R-squared is employed for calculating the fitness of the model.

$$
\begin{gathered}
\text { MAE }=\frac{1}{n} \sum_{i=1}^{n}\left|x_{i}-x_{i}^{\prime}\right| \\
\text { RMSE }=\sqrt{\frac{1}{n} \sum_{i=1}^{n}\left(x_{i}-x_{i}^{\prime}\right)^{2}} \\
\text { MAPE }=\frac{1}{n} \sum_{i=1}^{n}\left|\frac{x_{i}-x_{i}^{\prime}}{x_{i}}\right| \times 100 \%
\end{gathered}
$$




$$
R_{- \text {Squared }}=1-\frac{\sum_{i}^{n}\left(x_{i}-x_{i}^{\prime}\right)^{2}}{\sum_{i}^{n}\left(x_{i}-\bar{x}_{i}\right)^{2}}
$$

where $n$ is the forecast sample number; $x_{i}$ is the value speed at time $i ; x_{i}^{\prime}$ is the forecasted value at time $i$; and $\bar{x}_{i}$ is the average of the true value at time $i$.

The initial parameters in this experiment were chosen from References [32,35]. Note that 10 tests were carried out to determine the optimal parameter values in FF and FPA models, concluded in Table 6. The neural network has 15 inputs, 10 neurons in the first hidden layer, 5 neurons in the second hidden layer and one output.

Table 6. Parameter Settings.

\begin{tabular}{|c|c|c|c|c|c|}
\hline \multicolumn{6}{|c|}{ FF } \\
\hline $\begin{array}{c}\text { Input Layer } \\
\text { Neurons }\end{array}$ & $\begin{array}{l}\text { Hidden Layer } \\
\text { Neurons }\end{array}$ & $\begin{array}{l}\text { Output } \\
\text { Layer } \\
\text { Neurons }\end{array}$ & Iterations & Target Error & $\begin{array}{l}\text { Learning } \\
\text { Rate }\end{array}$ \\
\hline 5 & $10-5$ & 1 & 200 & 0.001 & 0.01 \\
\hline \multicolumn{6}{|c|}{ FPA } \\
\hline \multicolumn{3}{|c|}{ Population Number } & Iterations & \multicolumn{2}{|c|}{$\begin{array}{l}\text { Transition } \\
\text { Probability }\end{array}$} \\
\hline 20 & \multicolumn{2}{|c|}{10} & 200 & \multicolumn{2}{|c|}{0.8} \\
\hline
\end{tabular}

From 1 March to 13 March, a total of 1872 samples were used for model implementation. After EEMD decomposition, 1772 samples of each IMF and RES were trained, and the last 100 samples were used to judge the prediction efficiency. Three models, i.e., EEMD-IFPA-FF, EEMD-FPA-FF and IFPA-FF, were evaluated and compared using the same wind speed data. The comparison between the predicted wind speeds and actual ones on 13 March is shown in Figure 11. It reveals that the predicted curve from EEMD-IFPA-FF model is relatively closer to the actual one than others.

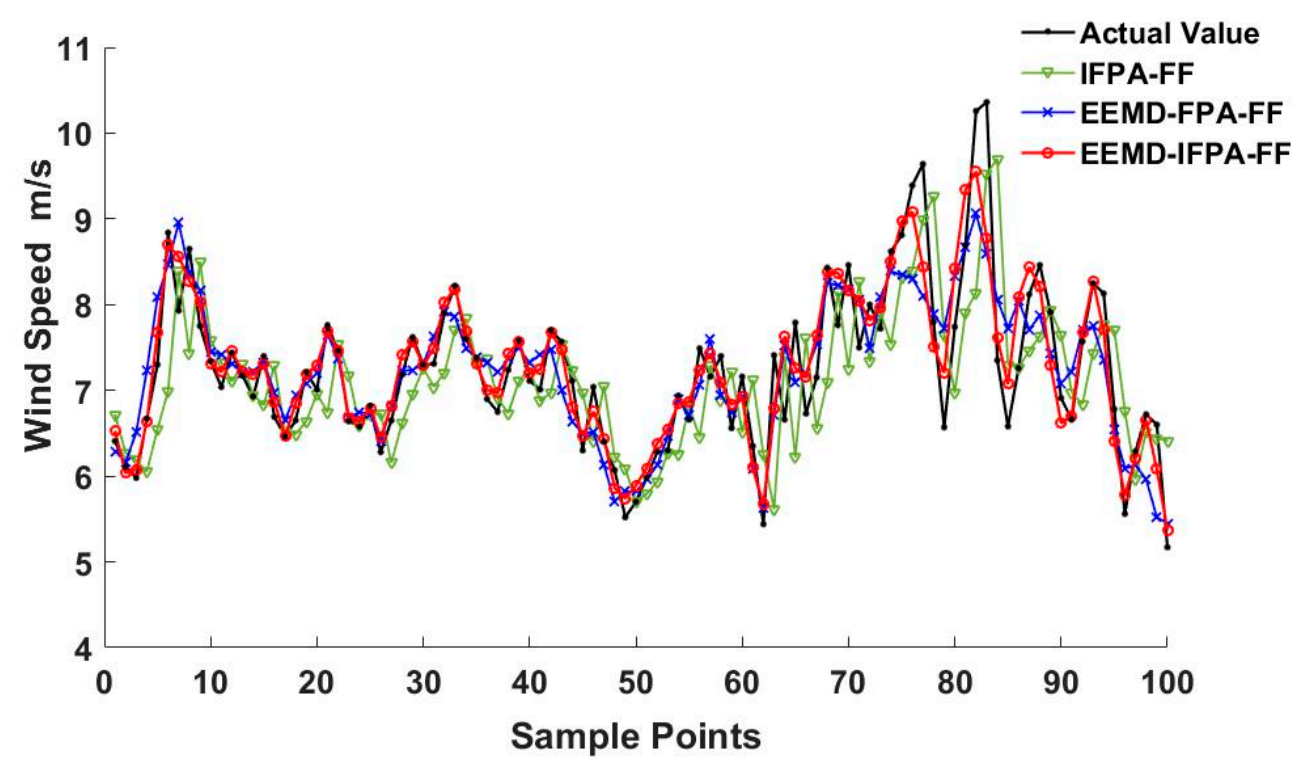

Figure 11. Wind speed prediction on 13 March.

Similarly, the performance test outcomes carried out on 13 February and 13 April can be seen in Figures 12 and 13, respectively. By comparing Figures 11-13, the wind speed data in February 
is relatively stable with less fluctuation and lower amplitude. As a result, each model was more accurate in February than in other months. This implies that the fluctuation of the wind speed and the magnitude is the major factor that may affect the prediction accuracy. The comparison of training samples with existing models is concluded in Table 7. The comparison of testing samples with existing models is concluded in Table 8.

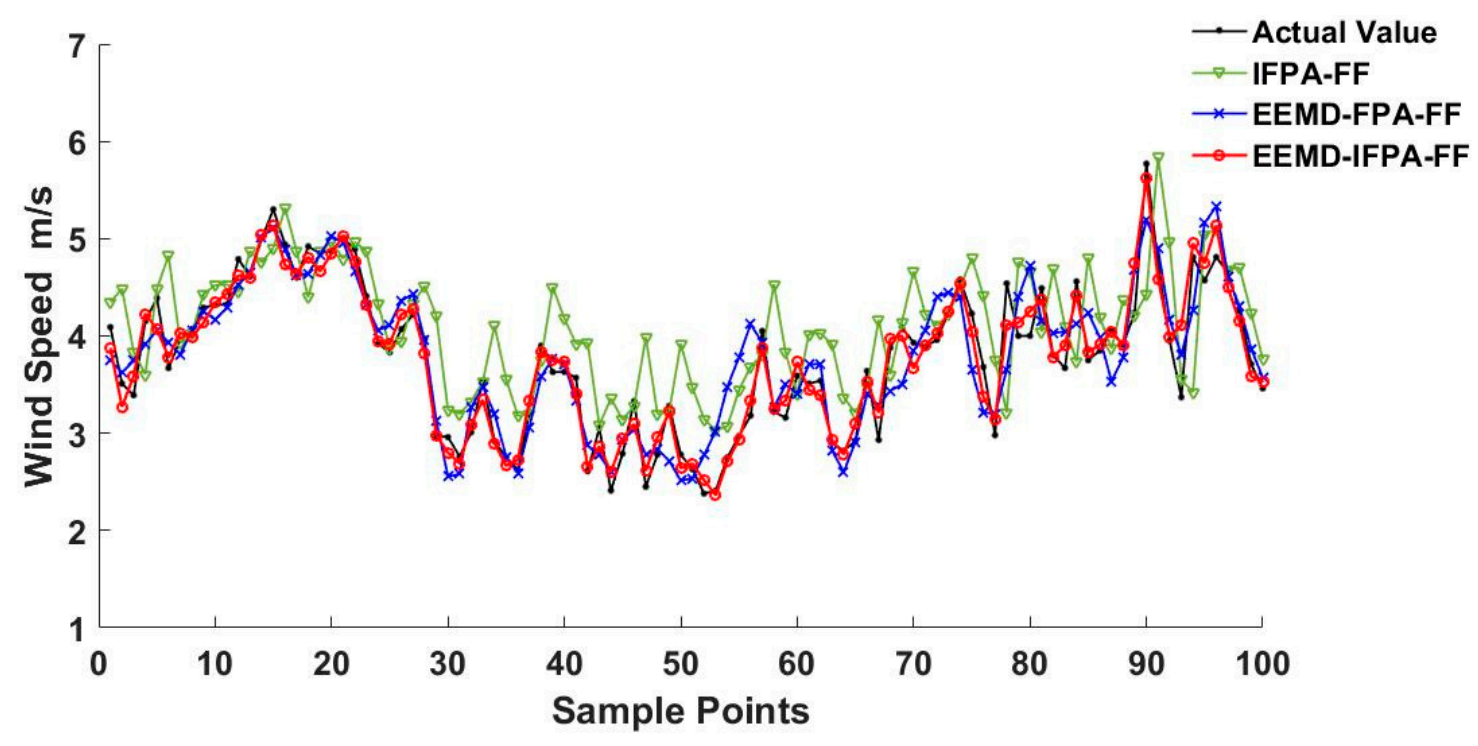

Figure 12. Wind speed prediction on 13 February.

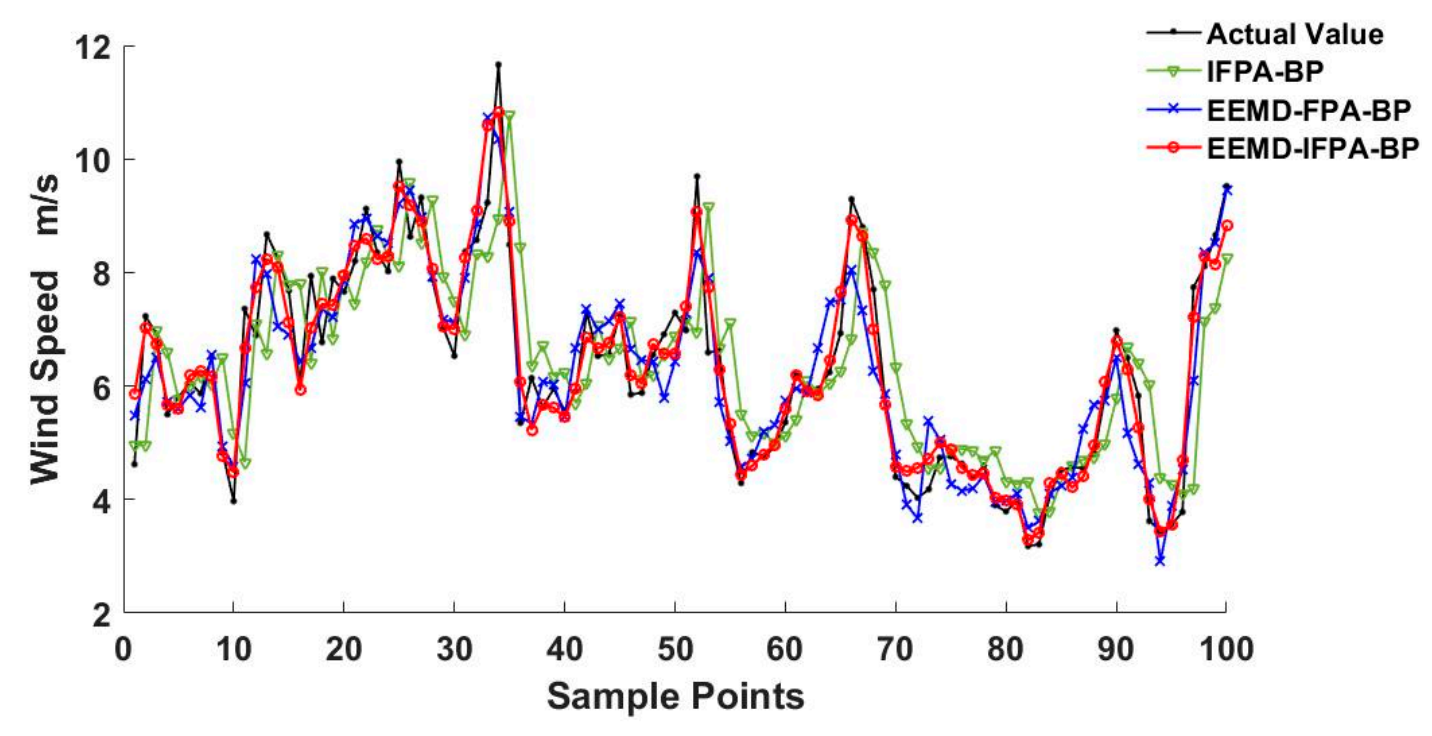

Figure 13. Wind speed prediction on 13 April.

Comparing the error results of Tables 7 and 8, the error of the test set slightly increases compared to the error of the training set. In both training and the test results analysis, the error from the IFPA-FF model performance can reach the smallest value, presenting a certain generalization ability. As shown in Figures 11-13, it is found that the wind speed trend prediction using IFPA-FF model has a lag behind the actual speed due to its randomness characteristics. On the other hand, the wind speed series predicted by EEMD-IFPA-FF model and EEMD-FPA-FF model are almost the same as the actual ones without any lag. In Table 8, the maxima errors appeared on 4.13 among three-days collected data. At this day, the MAE, RMSE and MAPE for IFPA-FF model is up to $0.75 \mathrm{~m} \cdot \mathrm{s}^{-1}, 0.89 \mathrm{~m} \cdot \mathrm{s}^{-1}$, and $14.67 \%$, respectively. In the EEMD-FPA-FF model, however, the MAE, RMSE and MAPE are down to below $0.51 \mathrm{~m} \cdot \mathrm{s}^{-1}, 0.68 \mathrm{~m} \cdot \mathrm{s}^{-1}$ and $10.74 \%$, respectively. In the EEMD-IFPA-FF model, the MAE, RMSE and 
MAPE are further improved to $0.37 \mathrm{~m} \cdot \mathrm{s}^{-1}, 0.43 \mathrm{~m} \cdot \mathrm{s}^{-1}$ and $8.33 \%$, respectively. Compared with the two other existing models, the MAE, RMSE and MAPE are reduced by more than $0.21 \mathrm{~m} \cdot \mathrm{s}^{-1}, 0.30 \mathrm{~m} \cdot \mathrm{s}^{-1}$ and $3.67 \%$, respectively. By investigating $R_{-S q u a r e d}$, it is confirmed that the EEMD-IPFA-FF reaches the highest fitness and achieves a better prediction. In conclusion, it is obvious that the prediction accuracy is considerably improved and relatively stable using the EEMD-IFPA-FF model.

Table 7. Error comparison of training samples with existing models.

\begin{tabular}{cccccc}
\hline Time & Model & MAE (m/s) & RMSE (m/s) & MAPE & R-Squared \\
\hline \multirow{3}{*}{13 February } & EEMD-IFPA-FF & 0.1988 & 0.2097 & $6.0071 \%$ & 0.8772 \\
& EEMD-FPA-FF & 0.3067 & 0.4077 & $7.1021 \%$ & 0.6912 \\
& IFPA-FF & 0.3982 & 0.5131 & $9.0831 \%$ & 0.3144 \\
\hline \multirow{3}{*}{13 March } & EEMD-IFPA-FF & 0.2119 & 0.3019 & $6.7411 \%$ & 0.8038 \\
& EEMD-FPA-FF & 0.4028 & 0.5257 & $9.2269 \%$ & 0.5981 \\
& IFPA-FF & 0.5229 & 0.6941 & $11.8581 \%$ & 0.4719 \\
\hline \multirow{3}{*}{13 April } & EEMD-IFPA-FF & 0.3102 & 0.3931 & $7.7103 \%$ & 0.7963 \\
& EEMD-FPA-FF & 0.4262 & 0.5733 & $9.7835 \%$ & 0.5492 \\
& IFPA-FF & 0.7038 & 0.8291 & $13.2210 \%$ & 0.4045 \\
\hline
\end{tabular}

Table 8. Error comparison of testing samples with existing models.

\begin{tabular}{cccccc}
\hline Time & Model & $\begin{array}{c}\text { MAE } \\
(\mathbf{m} / \mathbf{s})\end{array}$ & $\begin{array}{c}\text { RMSE } \\
(\mathbf{m} / \mathbf{s})\end{array}$ & MAPE & R-Squared \\
\hline \multirow{3}{*}{13 February } & EEMD-IFPA-FF & 0.2287 & 0.2584 & $6.2094 \%$ & 0.8594 \\
& EEMD-FPA-FF & 0.3871 & 0.4440 & $7.4302 \%$ & 0.6246 \\
& IFPA-FF & 0.4199 & 0.5670 & $9.9741 \%$ & 0.2049 \\
\hline \multirow{3}{*}{13 March } & EEMD-IFPA-FF & 0.3079 & 0.3695 & $7.2433 \%$ & 0.7789 \\
& EEMD-FPA-FF & 0.4590 & 0.5728 & $9.8365 \%$ & 0.5479 \\
& IFPA-FF & 0.5926 & 0.7802 & $12.9114 \%$ & 0.3942 \\
\hline \multirow{3}{*}{13 April } & EEMD-IFPA-FF & 0.3699 & 0.4303 & $8.3257 \%$ & 0.7436 \\
& EEMD-FPA-FF & 0.5128 & 0.6817 & $10.7430 \%$ & 0.5017 \\
& IFPA-FF & 0.7519 & 0.8924 & $14.6718 \%$ & 0.3370 \\
\hline
\end{tabular}

\section{Conclusions}

In this paper, the proposed EEMD-IFPA-FF prediction model has been well established for an optimization achievement. The FPA is enhanced by incorporating dynamic inertia weights in the IFPA algorithm. Therefore, a faster convergence speed can be achieved. Besides, the FF global search capability is improved to reach a global solution by integrating the IFPA. Moreover, the wind speed data was decomposed using the EEMD method to increase the prediction accuracy. Accordingly, it is obvious that the proposed model provides a better performance than other existing models in both convergence speed and prediction error no matter how small or large the wind speed fluctuates. Apart from the above, the $\mathrm{R}_{\text {-squared }}$ value further verifies the EEMD-IFPA-FF model presents the highest fitness value among existing models.

Author Contributions: All authors conceived the study. Y.R. and H.L. determined the simulation analysis program; Y.R. did data analysis and simulation experiments; Y.R. and H.-C.L. wrote the article; H.-C.L. reviewed the manuscript and provided valuable suggestions.

Funding: This work was supported by the National Natural Science Foundation of China (grant number 51777052), the Natural Science Foundation of Hebei province of China (grant number E2018202282) and the Natural Science Foundation of Tianjin province of China (grant number 19JCZDJC32100).

Conflicts of Interest: The authors declare no conflicts of interest. 


\section{References}

1. William, P.M.; Keith, P.; Gerry, W.; Liu, Y.B.; William, L.M.; Sun, J.Z.; Luca, D.M.; Thomas, H.; David, J.; Sue, E.H. A wind power forecasting system to optimize grid integration. IEEE Trans. Sustain. Energy 2012, 3, 670-682.

2. Wang, J.; Song, Y.; Liu, F.; Hou, R. Analysis and application of forecasting models in wind power integration: A review of multi-step-ahead wind speed forecasting models. Renew. Sustain. Energy Rev. 2016, 60, 960-981. [CrossRef]

3. Kavousi-Fard, A.; Khosravi, A.; Nahavandi, S. A New Fuzzy-Based Combined Prediction Interval for Wind Power Forecasting. IEEE Transa. Power Syst. 2015, 31, 1-9. [CrossRef]

4. Madhiarasan, M.; Deepa, S.N. Comparative analysis on hidden neurons estimation in multi layer perceptron neural networks for wind speed forecasting. Artif. Intell. Rev. 2017, 48, 449-471. [CrossRef]

5. Garcia-Ruiz, R.A.; Blanco-Claraco, J.L.; Lopez-Martinez, J.; Callejon-Ferre, A.J. Uncertainty-Aware Calibration of a Hot-Wire Anemometer With Gaussian Process Regression. IEEE Sens. J. 2019, 19, 7515-7524. [CrossRef]

6. Sial, A.; Singh, A.; Mahanti, A.; Gong, M. Heuristics-Based Detection of Abnormal Energy Consumption. Smart Grid Innov. Front. Telecommun. 2018, 245, 21-31.

7. Sial, A.; Singh, A.; Mahanti, A. Detecting anomalous energy consumption using contextual analysis of smart meter data. Wirel. Netw. J. 2019, 245, 1-18. [CrossRef]

8. Wang, Y.; Ma, H.; Wang, D.; Wang, G.; WU, J.; Bian, J.; Liu, J. A new method for wind speed forecasting based on copula theory. Environ. Res. 2018, 160, 365-371. [CrossRef]

9. Li, L.L.; Sun, J.; Wang, C.H.; Zhou, Y.T.; Lin, K.P. Enhanced Gaussian Process Mixture Model for Short-Term Electric Load Forecasting. Inf. Sci. 2019, 477, 386-398. [CrossRef]

10. Piotrowski, P.; Baczynski, D.; Kopyt, M.; Szafranek, K.; Helt, P.; Gulczynskl, T. Analysis of forecasted meteorological data (NWP) for efficient spatial forecasting of wind power generation. Electr. Power Syst. Res. 2019, 175, 105891. [CrossRef]

11. Wang, J.Z.; Wang, S.Q.; Yang, W.D. A novel non-linear combination system for short-term wind speed forecast. Renew. Energy 2019, 143, 1172-1192. [CrossRef]

12. Liu, H.; Mi, X.W.; Li, Y.F.; Duan, Z.; Xu, Y. Smart wind speed deep learning based multi-step forecasting model using singular spectrum analysis, convolutional Gated Recurrent Unit network and Support Vector Regression. Renew. Energy 2019, 143, 842-854. [CrossRef]

13. Zhao, J.; Guo, Z.; Su, Z.; Zhao, Z.; Xiao, X.; Liu, F. An improved multi-step forecasting model based on WRF ensembles and creative fuzzy systems for wind speed. Appl. Energy 2016, 162, 808-826. [CrossRef]

14. Nalcaci, G.; Ozmen, A.; Weber, G.W. Long-term load forecasting: Models based on MARS, ANN and LR methods. Cent. Eur. J. Oper. Res. 2019, 27, 1033-1049. [CrossRef]

15. Madhiarasan, M.; Deepa, S.N. A novel criterion to select hidden neuron numbers in improved back propagation networks for wind speed forecasting. Appl. Intell. 2016, 44, 878-893. [CrossRef]

16. Wang, J.Z.; Wang, Y.; Jiang, P. The study and application of a novel hybrid forecasting model—A case study of wind speed forecasting in China. Appl. Energy 2015, 143, 472-488. [CrossRef]

17. Tascikaraoglu, A.; Sanandaji, B.M.; Poolla, K.; Varaiya, P. Exploiting sparsity of interconnections in spatio-temporal wind speed forecasting using Wavelet Transform. Appl. Energy 2016, 165, 735-747. [CrossRef]

18. Alhussein, M.; Harider, S.L.; Aurangzeb, K. Microgrid-Level Energy Management Approach Based on Short-Term Forecasting of Wind Speed and Solar Irradiance. Energies 2019, 12, 1482. [CrossRef]

19. Liu, Z.F.; Li, L.L.; Tseng, M.L.; Raymond, R.T.; Kathleen, B.A. Improving the reliability of photovoltaic and wind power storage systems using least squares support vector machine optimized by improved chicken swarm algorithm. Appl. Sci. 2019, 9, 3788. [CrossRef]

20. Ding, M.; Zhou, H.; Xie, H. A gated recurrent unit neural networks based wind speed error correction model for short-term wind power forecasting. Neurocomputing 2019, 365, 54-61. [CrossRef]

21. Zhao, W.; Wei, Y.M.; Su, Z. One day ahead wind speed forecasting: A resampling-based approach. Appl. Energy 2016, 178, 886-901. [CrossRef]

22. Wang, H.Z.; Li, G.Q.; Wang, G.B.; Peng, J.; Jiang, H.; Liu, Y. Deep learning based ensemble approach for probabilistic wind power forecasting. Appl. Energy 2017, 188, 56-70. [CrossRef] 
23. Ding, Y. A novel decompose-ensemble methodology with AIC-ANN approach for crude oil forecasting. Energy 2018, 154, 328-336. [CrossRef]

24. Mohammed, A.; Tomás, M. A review of modularization techniques in artificial neural networks. Artif. Intell. Rev. 2019, 52, 527-561.

25. Abdel-Basset, M.; Shawky, L.A. Flower pollination algorithm: A comprehensive review. Artif. Intell. Rev. 2018, 52, 1-25. [CrossRef]

26. Li, L.L.; Liu, Z.F.; Tseng, M.L. Enhancing the Lithium-ion battery life predictability using a hybrid method. Appl. Soft Comput. J. 2019, 74, 110-121. [CrossRef]

27. Lei, X.; Fang, M.; Wu, F.X.; Chen, L. Improved flower pollination algorithm for identifying essential proteins. BMC Syst. Biol. 2018, 12, 46. [CrossRef]

28. Li, L.L.; Zhang, X.B.; Tseng, M.L.; Lim, M.; Han, Y. Sustainable energy saving: A junction temperature numerical calculation method for power insulated gate bipolar transistor module. J. Clean. Prod. 2018, 185, 198-210. [CrossRef]

29. Sabeti, M.; Boostani, R.; Davoodi, B. Improved particle swarm optimization to estimate bone age. IET Image Process. 2018, 12, 179-187. [CrossRef]

30. Yuan, C.; Wang, J.; Yi, G. Estimation of key parameters in adaptive neuron model according to firing patterns based on improved particle swarm optimization algorithm. Mod. Phys. Lett. B 2017, 31, 1750060. [CrossRef]

31. Yang, Y.K.; Jiao, S.J.; Wang, W.F. Cooperative media control parameter optimization of the integrated mixing and paving machine based on the fuzzy cuckoo search algorithm. J. Vis. Commun. Image Represent. 2019, 63, 102591. [CrossRef]

32. Li, L.L.; Lv, C.M.; Tseng, M.L.; Song, M.L. Renewable energy utilization method: A novel Insulated Gate Bipolar Transistor switching losses prediction model. J. Clean. Prod. 2018, 176, 852-863. [CrossRef]

33. Hu, J.; Wang, J. Wind and solar power probability density prediction via fuzzy information granulation and support vector quantile regression. Int. J. Electr. Power Energy Syst. 2019, 113, 515-527.

34. Li, J.H.; Dai, Q. A new dual weights optimization incremental learning algorithm for time series forecasting. Appl. Intell. 2019, 49, 3668-3693. [CrossRef]

35. Li, B.; Zhang, L.; Zhang, Q.; Yang, S.M. An EEMD-Based Denoising Method for Seismic Signal of High Arch Dam Combining Wavelet with Singular Spectrum Analysis. Shock Vib. 2019, 2019, 1-9. [CrossRef]

36. Tan, Q.F.; Lei, X.H.; Wang, X.; Wang, H.; Wen, X.; Ji, Y.; Kang, A.Q. An adaptive middle and long-term runoff forecast model using EEMD-ANN hybrid approach. J. Hydrol. 2018, 567, 767-780. [CrossRef] 